\title{
Tecnologia e Educação
}

\section{Sandra Novaes Franzini Sutilo}

emebcarlina@tiete.sp.gov.br

EMEB. "Prof. a Carlina Alves de Lima" - Tietê - SP - Brasil

\section{Resumo}

Um olhar reflexivo sobre a EMEB "Prof Carlina Alves de Lima" mostrou alguns problemas que devem ser atacados para um melhor desempenho escolar dos alunos. Os últimos resultados das avaliações externas mostraram que a escola não conseguiu atingir as metas estabelecidas pelo MEC, medidas através do IDEB (Índice de Desenvolvimento da Educação Básica). No SARESP (Sistema de Avaliação do Rendimento Escolar do Estado de São Paulo) ela ficou no nível adequado e na ANA (Avaliação Nacional da Alfabetização) foi observada a grande concentração de alunos no nível 1 e 2, onde conclui-se que as dificuldades são mais acentuadas nas séries iniciais. Os resultados das avaliações internas vêem ao encontro das externas e nos mostram que as disciplinas de Língua Portuguesa e Matemática são as responsáveis por estes dados que nos preocupam e reprovam em nossa escola, mostrando a ineficiência do nosso trabalho relacionado a recuperação de estudos. A escola Carlina possui um laboratório de Informática pouco utilizado com a necessidade de uma revitalização. As crianças valorizam e se mostram muito motivados pelos recursos digitais e seus desafios. Identifiquei, portanto, uma oportunidade de inserir uma aula semanal de Português/Matemática, intercalando semanalmente essas duas disciplinas na Sala de Informática para melhorar não só a motivação, mas o desempenho dos alunos. Para este empreendimento utilizarei o valor de $\mathrm{R} \$ 34.873,58$, que se encontra na categoria $B$, através do edital que será empregado para melhoria de infraestrutura e modernização do espaço e para contratação de um professor formador para orientar o corpo docente com o trabalho das disciplinas citadas com a utilização de softwares. Como contrapartida, a escola pode oferecer o trabalho de toda equipe escolar e uma estrutura adequada para as aulas em questão estimada em $\mathrm{R} \$ 12.256,50$. Os objetivos estratégicos do projeto concentram-se sobre os problemas apresentados no diagnóstico da escola, ou seja, aumentar a quantidade de habilidades adquiridas em Língua Portuguesa e Matemática em todo ciclo I, prioritariamente nos anos iniciais, tornando as aulas motivadoras e atrativas, pois farão parte do contexto social dos alunos que são frutos da era digital e desse modo garantindo melhores índices de aprendizagem. As "Tecno-aulas" aqui propostas utilizam os recursos tecnológicos aumentando o interesse dos alunos pelos conteúdos a serem ensinados. Eles utilizarão o laboratório de Informática e terão acesso a softwares que permitirão trabalhar de maneira diversificada e prazerosa as habilidades que deixaram de ser adquiridas no decorrer do processo de aprendizagem. Todos os anos serão contemplados com esta inovação, mas haverá nos três anos iniciais uma avaliação com maior periodicidade. O plano de empreendimento "Tecnologia e Educação" trará grande retorno à escola, pois será um estimulo aos alunos a estudar e atingir uma educação de excelência, missão esta que a escola busca galgar.

Palavras-chaves: Plano de Empreendimento. Empreendedorismo e Educação. Tecnologia. 


\section{Caracterização da Escola}

A EMEB. "Prof. ${ }^{a}$ Carlina Alves de Lima", localizada em Tietê (SP) atende Ensino Fundamental - Ciclo I - $1^{0}$ ao $5^{\circ}$ ano e Sala de Recurso. A escola tem como missão "Oferecer um ensino de qualidade, que favoreça a autonomia, tendo em vista a transformação social, com respeito as diferenças e com sustentabilidade", e a visão de "ser reconhecida como instituição de educação que concretiza o processo ensino aprendizagem com qualidade, ética e comprometimento, se tornando referência na educação de excelência, sendo uma das cinco melhores classificadas no IDEB da nossa região em 2017, exemplo para o município também pelas ações transformadoras da realidade social.".

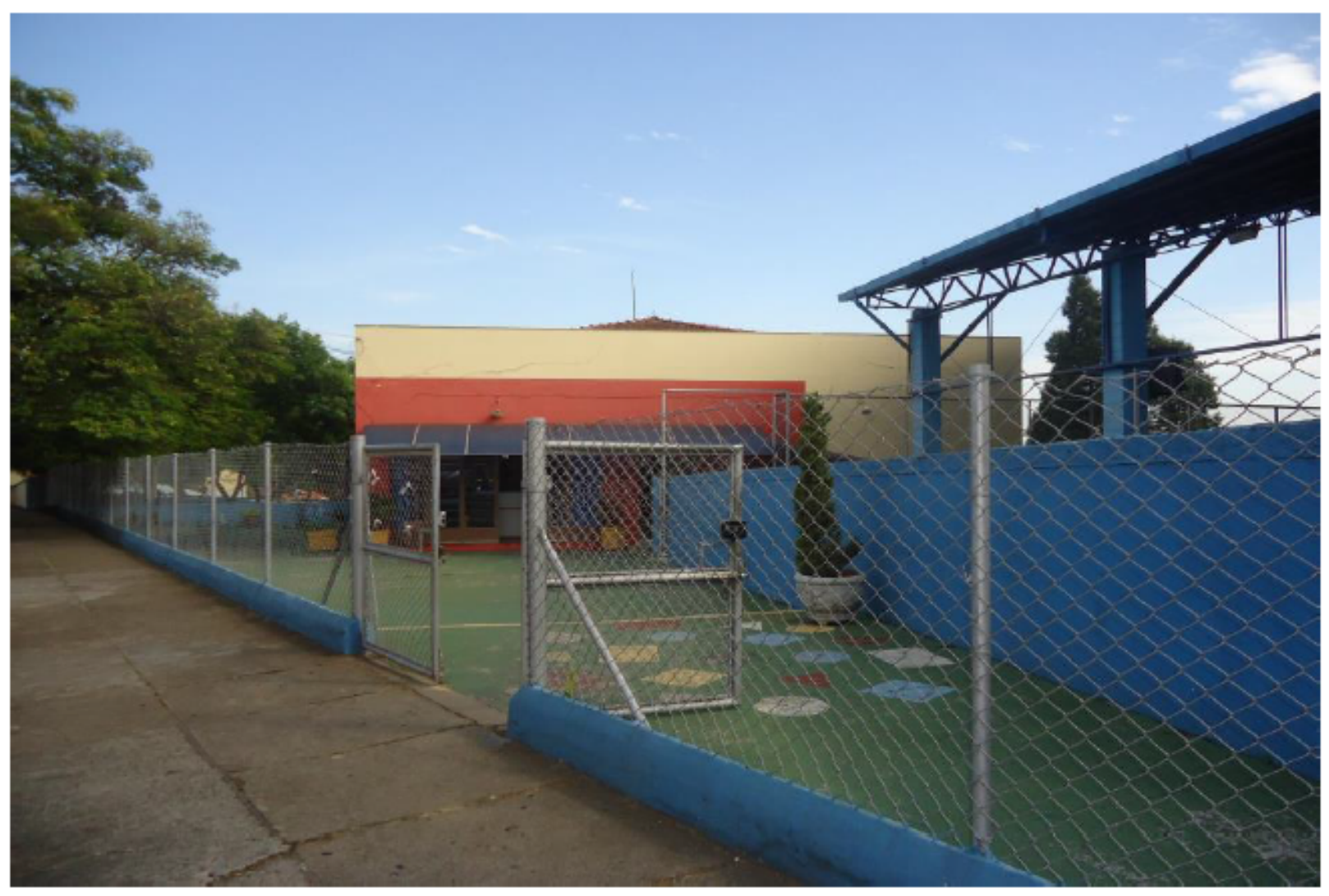

Figura 1: Foto da fachada da escola

\section{Instalações}

A área total da escola é de $5.020 \mathrm{~m} 2$, sendo $1.875 \mathrm{~m} 2$ de área construída e $3.145 \mathrm{~m} 2$ de área livre. Ela possui 2 pavimentos com 12 salas de aula, 6 banheiros, 1 quadra poliesportiva coberta, 1 sala de Direção, 1 Sala de Coordenação, 1 Secretaria, 1 Sala dos Professores, 1 Biblioteca adaptada, 1 Gabinete dentário, 1 Cozinha, 1 Refeitório, 1 cantina, 1 Pátio, 1 Sala de Informática, 1 almoxarifado e 1 zeladoria. Os espaços se encontram em bom estado de conservação precisando apenas de uma pintura já solicitada a Prefeitura Municipal de Tietê. 


\section{Breve histórico}

O quadro a seguir apresenta a relação dos acontecimentos mais relevantes para a evolução da escola, desde a fundação até hoje:

\begin{tabular}{|c|l|}
\hline \multicolumn{1}{|l|}{ Ano } & Acontecimentos relevantes \\
\hline 1966 & Criação da Escola - 20 Grupo Escolar de Tietê \\
\hline 1967 & Passou a Grupo Escolar Ginásio “Prof.a Carlina Alves de Lima” \\
\hline 1975 & Passou a denominar-se EEPG “Prof.a Carlina Alves de Lima” \\
\hline 1978 & Campeão pré-mirim futsal masculino \\
\hline 1979 & Campeão pré-mirim e mirim futsal masculino \\
\hline 1982 & Campeão Mirim vôlei feminino \\
\hline 1998 & Campeão Gincana Interescolar \\
\hline 1996 & Passou a atender somente o ciclo I do Ensino Fundamental \\
\hline 2004 & Recebeu o Selo Escola Solidária \\
\hline 2005 & Teve sua quadra coberta \\
\hline 2006 & Escola aberta aos fins de semana - Programa Escola da família \\
\hline 2009 & Com a Municipalização passou - EMEB “Prof.a Carlina Alves de Lima” \\
\hline 2012 & Implantação do Sistema SESI de Ensino \\
\hline
\end{tabular}

\section{Professores e funcionários}

A equipe é formada por quinze professores, distribuídos da seguinte forma:

\begin{tabular}{|l|c|}
\hline Disciplina / Área & Quant. de professores \\
\hline Classe Comum 17 & 17 \\
\hline Educação Especial 2 & 2 \\
\hline Arte 3 & 3 \\
\hline Educação Física 2 & 2 \\
\hline Inglês 1 & 1 \\
\hline Readaptada - Ciências 1 & 1 \\
\hline
\end{tabular}

Do total de professores, vinte e cinco são efetivos, uma é contratada e uma é readaptada. Todos possuem graduação equivalente a função que desempenham. Desta totalidade $55 \%$ também possuem especialização. Este grupo é bastante experiente, a média é de vinte anos de trabalho, sendo a maioria deles na mesma unidade escolar, embora desde 2013 esteja "perdendo" alguns profissionais devido a aposentadorias, basicamente dois ao ano, e conseqüentemente recebo novos que precisam de capacitação e acompanhamento. Uma situação bem peculiar, mas de muita troca, pois possuo pessoas acolhedoras no grupo que compartilham experiências de sucesso e procuram mostrar caminhos para os mais novos. Além disso, a escola conta com 10 funcionários de apoio, sendo 1 Diretor, 1 Orientador Pedagógico, 1 agente de Secretaria Escolar, 3 Agente de Organização Escolar, 2 Agente de Orientação Escolar, 2 Agentes de Desenvolvimento Infantil (Auxiliares das crianças com Necessidades Especiais). 


\section{Perfil dos alunos}

Os alunos estão distribuídos por séries e turnos da seguinte maneira:

\begin{tabular}{|c|c|c|c|c|c|c|}
\hline \multirow{2}{*}{ Série/Ano } & \multirow{2}{*}{$\begin{array}{c}\text { Média de } \\
\text { idade }\end{array}$} & \multirow{2}{*}{$\begin{array}{c}\text { Total de } \\
\text { alunos }\end{array}$} & Manhã & \multicolumn{3}{|c|}{ Tarde } \\
\cline { 5 - 7 } & & $\mathbf{N}^{0}$ alunos & No turmas & $\mathbf{N}^{0}$ alunos & $\mathbf{N}^{0}$ turmas \\
\hline $1^{0}$ ano & 6,5 & 94 & 48 & 2 & 46 & 2 \\
\hline $2^{\circ}$ ano & 7,5 & 55 & 28 & 1 & 27 & 1 \\
\hline $3^{\circ}$ ano & 8,5 & 96 & 49 & 2 & 47 & 2 \\
\hline $4^{\circ}$ ano & 9,5 & 99 & 57 & 2 & 42 & 2 \\
\hline $5^{\circ}$ ano & 10,5 & 93 & 61 & 2 & 32 & 2 \\
\hline Sala Recurso & 12,5 & 6 & 2 & 1 & 4 & 1 \\
\hline TOTAL & - & 443 & 245 & 10 & 198 & 9 \\
\hline
\end{tabular}

Nossa clientela escolar é composta de $50,91 \%$ do gênero feminino e $49,9 \%$ do gênero masculino. Quanto a cor/raça $71 \%$ são brancos, $24 \%$ pardos e $4 \%$ pretos e apenas 3,55 apresentam alguma deficiência. Em relação a distância da escola $96 \%$ residem até $5 \mathrm{~km}$ da escola e 4\% residem de 6 a $10 \mathrm{Km}$. São beneficiados pela Bolsa família $14 \%$ - sendo que $86 \%$ não recebem. No que tange a renda familiar $61 \%$ recebem entre $2 \mathrm{e}$ 3 salários mínimos.

Esses alunos são provenientes de diferentes bairros, $64 \%$ utilizam ônibus escolar, $21 \%$ utilizam carro e somente $15 \%$ vêm a pé, pois residem até $1,5 \mathrm{~km}$ de distância da escola, o que significa que não tenho alunos que residem no meu entorno próximo. 0 transporte escolar é oferecido pela Prefeitura Municipal que oferece este serviço a crianças que residem em no mínimo de $1,5 \mathrm{~km}$ de distância da escola. No período da manhã a maioria dos alunos fica com familiares no contra turno e freqüentam atividades diversas como música, balé, etc., já as crianças do período da tarde, em sua grande maioria, vem de Projetos como "Educandário Rosa Mística", "Casa de Maria" e "Casa dos Meninos", onde ficam no período da manhã, pois os pais trabalham o dia todo e vem direto para a escola.

Diante desses dados tenho duas realidades diferentes na escola em que trabalho. Alunos do período da manhã: crianças mais disciplinadas e com famílias mais participativas e envolvidas no processo de aprendizagem dos filhos. Alunos do período da tarde: maiores problemas de indisciplina, pais mais resistentes a participação.

\section{Características do entorno}

A Escola Carlina é central, bem localizada, próxima a área comercial do município. A alguns metros se localiza a antiga rodoviária, hoje terminal de circulares, lojas, lanchonetes, sorveterias e a praça central. Não possuímos muitas indústrias no município e a área que mais emprega é o comércio e as confecções infantis. Nossa zona rural é muito grande e a cultura que se destaca é a da cana-de-açúcar. $O$ único bairro rural atendido pela Escola em que atuo chama-se bairro Baronesa. À noite o local onde a escola está inserida, não é muito movimentado e, portanto tínhamos muitos problemas com invasões para uso de entorpecentes e "namoros" aos fins de semana o que foi minimizado com a colocação de um caseiro, além de monitoramento por câmeras e um investimento da escola com iluminação interna.

Um dos bairros que atendemos próximo a escola, a "Santa Cruz" é uma área de risco devido ao trafego e uso de drogas, portanto fizemos parceria com a polícia militar que desenvolve o PROERD e o Projeto Pelicano, assim tentamos minimizar os reflexos no futuro das crianças que vivem esse cotidiano violento. Como toda cidade do interior Tietê ainda é tranqüila, mas os reflexos da desestrutura familiar já se mostra dentro das escolas, seja por atitudes violentas das crianças ou por seu desinteresse aos estudos e este fato independe do bairro ou classe social, ele já se faz presente. 


\section{Identificação do Problema e da Oportunidade}

A identificação do problema partirá de um diagnóstico da Unidade Escolar. Para isso, foram observadas as principais avaliações externas, avaliações da equipe pedagógica, bem como relatórios internos de desempenho.

\section{IDEB}

\section{Resultado para $05^{\circ}$ ano}

\begin{tabular}{|c|c|c|c|c|c|c|c|c|c|}
\hline ANO & $\mathbf{2 0 0 5}$ & $\mathbf{2 0 0 7}$ & $\mathbf{2 0 0 9}$ & $\mathbf{2 0 1 1}$ & $\mathbf{2 0 1 3}$ & $\mathbf{2 0 1 5}$ & $\mathbf{2 0 1 7}$ & $\mathbf{2 0 1 9}$ & $\mathbf{2 0 2 1}$ \\
\hline Metas projetadas & - & - & 5.5 & 6.4 & 6.6 & 6.8 & 7.0 & 7.2 & 7.4 \\
\hline Ideb observado & - & - & 6,1 & 6,1 & 6,4 & - & - & - & - \\
\hline
\end{tabular}

Fonte: INEP

A escola apresenta um bom resultado no IDEB comparando com as demais escolas do município, ela é a primeira, porém não estamos conseguindo avançar para atingir as metas projetadas. A municipalização e as constantes mudanças do material pedagógico foram três de 2009 a 2013, até chegarmos a proposta sóciointeracionista com o material do SESI aliada a indecisão política sobre avaliação também prejudicaram 0 trabalho pedagógico. Hoje a escola tem a progressão continuada até o terceiro ano e a partir dele se necessário a retenção.

Abaixo se encontram distribuídos os níveis de acordo com a escala de proficiência demonstrando a necessidade de avanço nas competências e habilidades dos alunos.

\section{Prova Brasil $-5^{\circ}$ ano}

\begin{tabular}{|l|l|l|l|l|l|l|l|l|}
\hline \multicolumn{7}{|c|}{ Língua Portuguesa } \\
\hline Nível 1 & Nível 2 & Nível 3 & Nível 4 & Nível 5 & Nível 6 & Nível 7 & Nível 8 & $\begin{array}{l}\text { Nivel } \\
9\end{array}$ \\
\hline $10,88 \%$ & $11,68 \%$ & $12,5 \%$ & $21,15 \%$ & $16,72 \%$ & $10,49 \%$ & $14,42 \%$ & $2,16 \%$ & $0,0 \%$ \\
\hline
\end{tabular}

\begin{tabular}{|l|c|c|c|c|c|c|c|c|}
\hline \multicolumn{7}{|c|}{ Matemática } \\
\hline Nível 1 & Nível 2 & Nivel 3 & Nível 4 & Nível 5 & Nível 6 & Nível 7 & Nível 8 & Nível 9 \\
\hline $1,08 \%$ & $3,24 \%$ & $5,27 \%$ & $19,06 \%$ & $15,69 \%$ & $16,86 \%$ & $16,62 \%$ & $7,31 \%$ & $6,25 \%$ \\
\hline
\end{tabular}

Analisando os dados da Prova Brasil observamos uma porcentagem considerável de alunos encontra-se nos três primeiros níveis o que demonstra que estes alunos não dominam habilidades importantes para 0 ano que se encontram tanto em Português como em Matemática. 
ANA

\begin{tabular}{|c|c|c|c|}
\hline \multicolumn{3}{|c|}{ Leitura } \\
\hline Nível 1 & Nivel 2 & Nivel 3 & Nível 4 \\
\hline 6,26 & 27,90 & 39,68 & 28,16 \\
\hline
\end{tabular}

\begin{tabular}{|c|c|c|c|}
\hline \multicolumn{4}{|c|}{ Matemática } \\
\hline Nível 1 & Nível 2 & Nivel 3 & Nível 4 \\
\hline 5,42 & 30,77 & 28,28 & 35,52 \\
\hline
\end{tabular}

Nesta análise do ANA observamos a concentração grande de alunos nos níveis 1 e 2 que precisam ser melhor trabalhados.

\section{Avaliação estadual SARESP}

$2^{\circ}$ ano

\begin{tabular}{|l|l|l|l|l|l|l|l|}
\hline \multicolumn{4}{|c|}{ Língua Portuguesa } & \multicolumn{5}{c|}{ Matemática } \\
\hline Insuficiente & Básico & Pleno & Avançado & Insuficiente & Básico & Pleno & Avançado \\
\hline 1,1 & 58,0 & 29,5 & 11,4 & 2,2 & 25,3 & 46,2 & 26,4 \\
\hline
\end{tabular}

$3^{\circ}$ e $5^{\circ}$ anos

\begin{tabular}{|c|c|c|c|}
\hline \multicolumn{2}{|c|}{ Língua Portuguesa } & $3^{\circ}$ ano & $5^{\circ}$ ano \\
\hline $3^{\circ}$ ano & $5^{\circ}$ ano & 181,7 & 227,0 \\
\hline 181,7 & 225,9 & & \\
\hline
\end{tabular}

Obs: Na distribuição por nível de proficiência $03^{\circ}$ e $05^{\circ}$ ano em Língua Portuguesa. e Matemática Adequado

Ao fazermos uma análise nos dados do SARESP identificamos alguns dados que sinalizam uma necessidade de intervenção em relação ao trabalho da escola: 1) Alto índice de alunos do $2^{\circ}$ anos se encontra no nível básico em Língua Portuguesa - 58\%; 2) № $3^{\circ}$ ano e $5^{\circ}$ anos a maior parte dos alunos se encontram no nível adequado. 3) Observamos um pequeno avanço nesses dados em relação ao comparativo do ano anterior. 


\section{Avaliações e relatórios internos}

Analisando os resultados de 2014 podemos concluir que não temos problema de evasão na escola, mas o $\mathrm{n}^{0}$ de transferências é muito alto o que dificulta um trabalho de continuidade, existe uma flutuação muito grande, pois muitas famílias vão a procura de emprego e melhores condições de moradia e quando não encontram voltam e assim sucessivamente. Em relação à retenção nosso índice é de $0,80 \%$ um número menor que a média nacional.

\begin{tabular}{|c|c|c|c|c|c|c|c|}
\hline Série/Ano & $\begin{array}{l}\text { Matriculas } \\
\text { iniciais }\end{array}$ & Evasão & Transf. & $\begin{array}{l}\text { Matriculas } \\
\text { finais }\end{array}$ & Disciplinas & Aprov. & Reprov. \\
\hline \multirow{8}{*}{$1^{\circ}$ ano } & \multirow{8}{*}{83} & \multirow{8}{*}{0} & \multirow{8}{*}{27} & \multirow{8}{*}{56} & Português & 56 & 0 \\
\hline & & & & & Matemática & 56 & 0 \\
\hline & & & & & História & 56 & 0 \\
\hline & & & & & Geografia & 56 & 0 \\
\hline & & & & & Cièncias & 56 & 0 \\
\hline & & & & & L. Estrangeira & 56 & 0 \\
\hline & & & & & Ed. Física & 56 & 0 \\
\hline & & & & & Artes & 56 & 0 \\
\hline \multirow{8}{*}{$2^{\circ}$ ano } & \multirow{8}{*}{110} & \multirow{8}{*}{0} & \multirow{8}{*}{16} & \multirow{8}{*}{94} & Português & 94 & 0 \\
\hline & & & & & Matemática & 94 & 0 \\
\hline & & & & & História & 94 & 0 \\
\hline & & & & & Geografia & 94 & 0 \\
\hline & & & & & Ciências & 94 & 0 \\
\hline & & & & & L. Estrangeira & 94 & 0 \\
\hline & & & & & Ed. Física & 94 & 0 \\
\hline & & & & & Artes & 94 & 0 \\
\hline \multirow{8}{*}{$3^{\circ}$ ano } & \multirow{8}{*}{117} & \multirow{8}{*}{0} & \multirow{8}{*}{16} & \multirow{8}{*}{101} & Português & 97 & 4 \\
\hline & & & & & Matemática & 97 & 4 \\
\hline & & & & & Histónia & 101 & 0 \\
\hline & & & & & Geografia & 101 & 0 \\
\hline & & & & & Ciências & 97 & 4 \\
\hline & & & & & L. Estrangeira & 101 & 0 \\
\hline & & & & & Ed. Física & 101 & 0 \\
\hline & & & & & Artes & 101 & 0 \\
\hline \multirow{8}{*}{$4^{\circ}$ ano } & \multirow{8}{*}{106} & \multirow{8}{*}{0} & \multirow{8}{*}{11} & \multirow{8}{*}{95} & Português & 95 & 0 \\
\hline & & & & & Matemática & 95 & 0 \\
\hline & & & & & História & 95 & 0 \\
\hline & & & & & Geografia & 95 & 0 \\
\hline & & & & & Ciências & 95 & 0 \\
\hline & & & & & L. Estrangeira & 95 & 0 \\
\hline & & & & & Ed. Física & 95 & 0 \\
\hline & & & & & Artes & 95 & 0 \\
\hline \multirow{8}{*}{$5^{\circ}$ ano } & \multirow{8}{*}{109} & \multirow{8}{*}{0} & \multirow{8}{*}{24} & \multirow{8}{*}{85} & Português & 84 & 1 \\
\hline & & & & & Matemática & 84 & 1 \\
\hline & & & & & História & 84 & 1 \\
\hline & & & & & Geografia & 84 & 1 \\
\hline & & & & & Cièncias & 84 & 1 \\
\hline & & & & & L. Estrangeira & 84 & 1 \\
\hline & & & & & Ed. Física & 85 & 0 \\
\hline & & & & & Artes & 85 & 0 \\
\hline
\end{tabular}




\section{Pesquisa}

Foi feita uma pesquisa descritiva através de um questionário para identificar o nível de satisfação com os serviços oferecidos pela escola: Questionário Anexo

Minha amostra foi definida da seguinte forma, optei por definir que metade dos questionários fosse respondido por clientes - pais (desses pais parte dos escolhidos foram os que participam dos órgãos colegiados e o restante aleatoriamente, ou melhor, aqueles que possuíam e-mail para envio do formulário) e metade usuários - alunos de $4^{\circ}$ e $5^{\circ}$ anos. Utilizei uma amostra não-probalística. Informo ainda que defini este total devido a dificuldade de acesso ao e-mail dos pais e alunos, embora saiba que é um $n^{0}$ pequeno mas é 0 que foi possível pelo tempo. Enfim dos 180 questionários enviados (90 para pais e 90 para alunos) obtive 162 devolutivas.

A maioria dos alunos e dos pais analisaram os seguintes pontos como excelente: a parte física da escola, como instalações, espaço físico, as aulas ministradas pelos professores, os materiais e recursos didáticos utilizados, os serviços da secretaria, a cordialidade do atendimento dos funcionários e a merenda escolar. Já a biblioteca é vista pelos alunos como nível bom, mas pelos pais como regular. $E$ a sala de informática teve nível bom para ambos, pais e filhos. A pesquisa demonstra que a escola está tendo bom desenvolvimento e aponta alguns itens que devem ser melhorados.

\section{Principais problemas identificados}

Após análise dos resultados e por já termos esta visão de conversas anteriores com o grupo de professores verificamos que a insatisfação está basicamente na biblioteca escolar e na sala de informática. A biblioteca foi desativada quando precisamos utilizar o seu espaço para a sala de aula e a sala de informática necessita de uma revitalização assim como projetos bem elaborados para sua utilização adequada, além de capacitações para os professores.

\begin{tabular}{|l|c|c|c|c|c|}
\hline \multicolumn{1}{|c|}{ Problemas } & G & U & T & GxUxT & Prioridade \\
\hline $\begin{array}{l}\text { Rendimento Insatisfatório em Português e } \\
\text { Matemática nos anos iniciais }\end{array}$ & 5 & 5 & 4 & 100 & $1^{0}$ \\
\hline Sala de informática & 5 & 4 & 4 & 80 & $2^{0}$ \\
\hline Biblioteca & 5 & 4 & 4 & 80 & $2^{\circ}$ \\
\hline
\end{tabular}




\section{Detalhamento do problema}

Utilizou-se o Diagrama de Causa e Efeito para detalhar o problema:

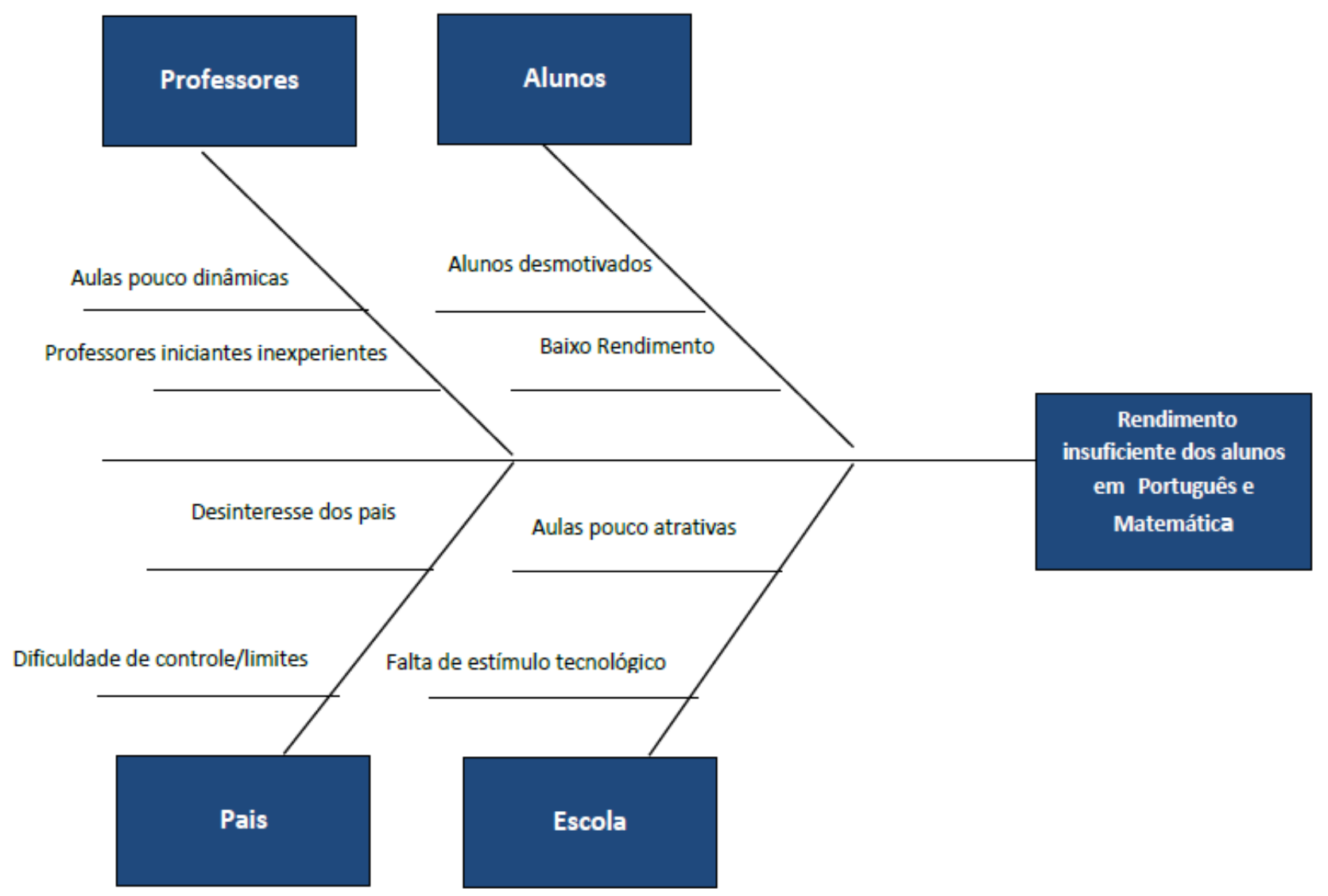




\section{Análise SWOT}

A partir das pesquisas realizadas pela equipe escolar e das discussões sobre o contexto da escola, foi desenvolvida a seguinte Matriz SWOT.

\begin{tabular}{|c|c|c|}
\hline & Aspectos favoráveis & Aspectos desfavoráveis \\
\hline \multirow[b]{2}{*}{ 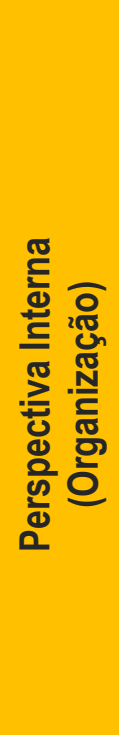 } & FORÇAS & FRAQUEZAS \\
\hline & $\begin{array}{l}\text { 1) Corpo Docente qualificado e } \\
\text { extremamente comprometido; } \\
\text { 2) Projeto Político Pedagógico construído } \\
\text { em parceria com a comunidade escolar; } \\
\text { 3) Escola bem equipada em relação aos } \\
\text { recursos didáticos. } \\
\text { 4) Possui boa reputação junto à sociedade } \\
\text { devido a sua qualidade educacional. }\end{array}$ & $\begin{array}{l}\text { 1) Após a municipalização do Ensino } \\
\text { existem duas situações de professores na } \\
\text { escola: os da parceria (Estado) e os efetivos } \\
\text { do município, o que gera em alguns } \\
\text { momentos competitividade } \\
\text { estranhamento. } \\
\text { 2) Despreparo de alguns funcionários de } \\
\text { empresas terceirizadas para trabalhar no } \\
\text { ambiente escolar. (limpeza e cozinha) } \\
\text { 3) Parte do grupo de professores tem } \\
\text { dificuldade em trabalhar com os recursos } \\
\text { tecnológicos. }\end{array}$ \\
\hline \multirow[b]{2}{*}{ 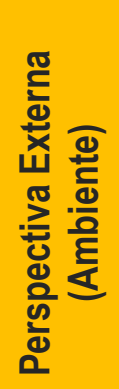 } & OPORTUNIDADES & AMEAÇAS \\
\hline & $\begin{array}{l}\text { 1) Apoio e parceria da comunidade escolar } \\
\text { que embora não seja do entorno é muito } \\
\text { participativa; } \\
\text { 2) Escola Central, bem localizada, próxima a } \\
\text { espaços educativos; }\end{array}$ & $\begin{array}{l}\text { 1) Mudanças das Políticas Públicas a cada } \\
\text { eleição o que ocasiona interrupção no } \\
\text { trabalho pedagógico para atender a nova } \\
\text { visão educacional; } \\
\text { 2) Excesso de exigências burocráticas; }\end{array}$ \\
\hline
\end{tabular}

A instituição que eu atuo tem muito mais forças e oportunidades que ameaças e fraquezas e 0 mais importante a meu ver que o grupo de trabalho é muito comprometido e isso faz toda diferença pois com um grupo unido e envolvido as possibilidades de obtenção de sucesso são muito grandes. Eles fazem acontecer.

Desta forma qualquer projeto que vise a melhora da aprendizagem dos alunos será abraçada pela equipe.

\section{Ações corretivas}

Visando preparar a organização para o desenvolvimento do projeto, no intuito de combater as fraquezas e reduzir os possíveis impactos das ameaças, foram definidas as seguintes ações:

- Promover momentos de interação e trabalho em duplas para que sejam superadas as diferenças entre dois grupos de professores existentes na escola e incentivar situações de descontração em que compartilhem vivencia e experiências pessoais e profissionais,

-Solicitar formação aos funcionários terceirizados fazendo com que entendam como deve ser feito o trabalho em uma escola e como devem se comportar com os alunos; 
-Incentivar a participação política de toda comunidade escolar para que fortalecidos e unidos façamos com que os futuros candidatos a prefeito entendam e se comprometam com a continuidade do trabalho educativo, pois ela é fundamental para a melhoria da qualidade do ensino;

-Capacitar os professores para o trabalho na Sala de Informática.

\section{Oportunidade identificada}

A ideia central é a revitalização do laboratório de informática, adquirindo softwares e equipamentos para as substituições necessárias, além de capacitar os professores para esta prática dentro das expectativas de aprendizagem esperadas para cada série/ano, viabilizando esse importante recurso no estímulo para aquisição de aprendizagem.

Com esta ação espera-se vir ao encontro dos anseios dos alunos e dos pais. É uma forma de desafiar e motivar os alunos saindo do cotidiano de giz e lousa e inserindo-os no mundo digital. Visa-se fazer com que os alunos considerados insuficientes em Português e Matemática avancem e consigam, estimulados por novos recursos, superar suas dificuldades.

\section{Detalhamento do produto/serviço e/ou processo}

\section{Foco do projeto}

Integrar a tecnologia no cotidiano da escola através da sala de informática considerando-a uma nova alternativa para educar, favorecendo desta forma o desenvolvimento do processo de ensino e aprendizagem.

Série ou conjunto de séries beneficiadas: $1^{\circ}, 2^{\circ}, 3^{\circ}, 4^{\circ}$ e $5^{\circ}$ anos.

Disciplina ou conjunto de disciplinas trabalhadas: Português e Matemática

Etapas do projeto: O projeto será composto pelas seguintes etapas:

\section{Etapa 1 - Adequação estrutural da sala}

Objetivo: Deixar a sala visualmente mais aconchegante, organizada e funcional para sua utilização.

Impacto na aprendizagem: Este espaço será mais utilizado pelos alunos e professores e consequentemente será possível criar novas estratégias de ensino-aprendizagem o que garantirá uma aprendizagem mais significativa e eficaz aos alunos.

Atividades a serem realizadas: Algumas mudanças na parte elétrica, na pintura, na organização da disposição da sala e aquisição de mouses, teclados, dois computadores e softwares pedagógicos.

\section{Atividade 1.1}

Descrição: Serão feitas alterações em tomadas, pintura e nova organização do espaço.

Duração: Um mês

Recursos necessários: tintas, lixa, solvente, pincéis, tomadas, fios, canaletas, espelhos, fita crepe, pintor e eletricista.

Equipe envolvida: Diretor, Assessor, Agente de Organização Escolar e pais de alunos.

\section{Atividade 1.2}

Descrição: Serão feitos três orçamentos e a compra de: mouses e teclados para substituição dos que estão apresentando problemas, de mais dois computadores para que os alunos em aula utilizem em duplas por máquina e softwares pedagógicos.

Duração: um mês

Recursos necessários: mouses, teclados, dois computadores e softwares pedagógicos

Equipe envolvida: Diretor e Orientador Pedagógico 


\section{Etapa 2 - Formação dos professores}

Objetivo: Propiciar aos professores a aquisição de conhecimentos quanto às vantagens do computador como nova ferramenta didática no processo de ensinoaprendizagem, familiarizando-os com o hardware e softwares educativos e desenvolvendo competências na aplicação da informática educativa.

Impacto na aprendizagem: A segurança dos professores quanto à condução das aulas.

Atividades a serem realizadas: Capacitações e explanações de experiências de sucesso de professores que já utilizam esta prática pedagógica.

\section{Atividade 2.1}

Descrição: Serão contratados profissionais que possam fazer as capacitações nos HTPCs com oficinas práticas intercalando com depoimentos de sucesso de colegas da escola e de outra Unidade Escolar.

Duração: Três meses

Recursos necessários: Profissionais da área de informática, professores, softwares adquiridos, data show e a própria sala de informática.

Equipe envolvida: Diretor, Assessor, Orientador Pedagógico

\section{Atividade 2.2}

Descrição: Serão realizadas oficinas de capacitação prática nos HTPCs com profissionais especializados que demonstrarão de que forma a tecnologia pode ser inserida no contexto escolar, principalmente nas aulas dos professores.

\section{Duração: Um mês}

Recursos necessários: Profissionais da área de informática, professores, softwares adquiridos, data show e a própria sala de informática.

Equipe envolvida: Diretor, Assessor, Orientador Pedagógico e Professores

\section{Etapa 3 - Preparação do espaço para inauguração da Revitalização e funcionamento}

Objetivo: Tornar o espaço acessível ao público para que possam desfrutar de sua utilização Impacto na aprendizagem: Curiosidade e interesse por este novo espaço de aprendizagem.

Atividades a serem realizadas: Dia de festa para a inauguração da revitalização da Sala de Informática

\section{Atividade 3.1}

Descrição: Finalização da organização do espaço, definição da data, confecção de convites para alunos, pais, comunidade, secretaria municipal de educação, divulgação no facebook da escola.

Duração: Um mês

Recursos necessários: computadores, impressora, papel vergê para os convites das autoridades, arte do convite, bilhete para pais, coffe breack para o dia da inauguração

Equipe envolvida: Diretor, Assessor, Orientador Pedagógico, Professores e Agentes de Organização Escolar

\section{Etapa 4 - Organização e Início do Funcionamento da Sala de Informática}

Objetivo: Incentivar a utilização da Sala de Informática através de uma aula semanal de Português e/ou Matemática intercaladas e agendadas para cada classe.

Impacto na aprendizagem: Melhora no desempenho da leitura e escrita, processo de alfabetização mais facilitado e construção do conhecimento matemático de forma concreta utilizando jogos de raciocínio. 
Atividades a serem realizadas: Uma aula semanal pré-agendada por série e intercalada (uma semana Português, a seguinte Matemática) utilizando a sala de informática com apresentação de um plano de trabalho docente.

\section{Atividade 4.1}

Descrição: Planilha elaborada pelo Orientador Pedagógico para utilização semanal de cada classe com acompanhamento do trabalho.

Duração: Dois dias para iniciar e um semestre antes da $1^{\text {a }}$ avaliação.

Recursos necessários: Planilha de horários, computador, impressora, Plano de trabalho docente, softwares, internet

Equipe envolvida: Diretor, Assessor, Secretário, Orientador Pedagógico e Professores

\section{Atividade 4.2}

Descrição: Selecionar atividades utilizadas na sala de informática. Português: Alfabetização, Gêneros Textuais, Paragrafação, Ortografia, Separação de Sílabas, Construção de Frases e Textos. Matemática: Classe de Números Naturais, Tabelas, Gráficos, Jogo da Memória envolvendo as quatro operações matemáticas, Medidas: comprimento, massa, tempo, volume.

Duração: Mensal

Recursos necessários: Softwares, computador, impressora, Plano de trabalho docente, e internet

Equipe envolvida: Diretor, Assessor, Orientador Pedagógico e Professores

\section{Casos de sucesso}

Nome do Projeto: O Livro dos Sonhos

Nome da organização: SENAI - Serviço Nacional de Aprendizagem Industrial

Local: SENAI NEAD Bahia

Período em que foi realizado: Criado através da Portaria nº 522 em 09/04/1997 e funciona até hoje.

Breve relato do contexto anterior ao projeto: A desmotivação dos alunos e a falta de acompanhamento em suas atividades de casa e a extensão dos seus estudos, fez com que a unidade inovasse de forma a atingir os alunos da melhor forma, através de jogos eletrônicos.

Principais atividades desenvolvidas: O SENAI NEAD Bahia pensando no uso dos jogos eletrônicos na educação, lançou o Livro dos sonhos, jogo eletrônico educacional com o objetivo de acompanhar 0 aluno durante o período de estudo. Cada etapa do jogo foi elaborada de acordo com o planejamento educacional desenvolvido pelos professores e pedagogos, e os conteúdos discutidos nos cursos foram inseridos em forma de desafios aos personagens da história desenvolvida.

Resumo dos principais resultados alcançados: Os desafios se tornaram parte da avaliação do conteúdo estudado. O uso dos jogos na educação pelo SENAI NEAD

Bahia busca proporcionar um ensino tecnológico de qualidade, favorecendo a inclusão digital, estimulando a pesquisa de desenvolvimento e promovendo a inserção no mercado de trabalho.

Fonte: http://portais.fieb.org.br/potal.ead/casos-de-sucesso.html 


\section{Novidade trazida pelo projeto}

O projeto implantado na escola em que trabalho se distinguirá dos demais, pois toda equipe escolar estará mobilizada para que aconteça a inserção tecnológica no

âmbito escolar. O ponta-pé inicial foi à compra pela Prefeitura Municipal de Tietê de um programa onde os professores digitarão notas, acompanhamento de desempenho individual de alunos, da classe, de cada disciplina, enfim a equipe terá em gráficos e tabelas da evolução da aprendizagem de cada aluno e se comunicará com os pais digitalmente.

Diante disso e com o funcionamento da Sala de informática, a inserção de novas tecnologias na escola aproximará mais os alunos da realidade. As ferramentas tecnológicas devem servir de base para a criatividade, raciocínio e atitudes ativas para a produção do conhecimento. Os desafios que surgirão tanto para os professores como para os alunos atingirá um dos pilares da educação que é aprender a aprender. 0 que há de novo? A idéia já é antiga, mas para a escola Carlina é o novo olhar, comprometimento e anseio de fazer dar certo, pois nos dias atuais a dualidade lousa e giz se fazem obsoleta e pouco eficaz, despertar a atenção de forma desafiadora ainda é o desafio que almejamos alcançar com o projeto.

\section{Cronograma de execução}

\begin{tabular}{|c|c|c|c|c|c|c|c|c|c|c|c|c|c|}
\hline \multirow{2}{*}{\multicolumn{2}{|c|}{ Atlvidades }} & \multicolumn{4}{|c|}{ Ano 1} & \multicolumn{4}{|c|}{ Ano 2} & \multicolumn{4}{|c|}{ Ano 3} \\
\hline & & \multirow{2}{*}{$\begin{array}{l}\text { Jan- } \\
\text { Mar }\end{array}$} & \multirow{2}{*}{$\begin{array}{l}\text { Abr- } \\
\text { Jun }\end{array}$} & \multirow{2}{*}{$\begin{array}{l}\text { Jul- } \\
\text { Set }\end{array}$} & $\begin{array}{l}\text { Out- } \\
\text { Dez }\end{array}$ & \multirow{2}{*}{$\begin{array}{l}\text { Jan- } \\
\text { Mar }\end{array}$} & \multirow{2}{*}{$\begin{array}{l}\text { Abr- } \\
\text { Jun }\end{array}$} & \multirow{2}{*}{$\begin{array}{l}\text { Jur- } \\
\text { Set }\end{array}$} & \multirow{2}{*}{$\begin{array}{l}\text { Out- } \\
\text { Dez }\end{array}$} & \multirow{2}{*}{$\begin{array}{l}\text { Jan- } \\
\text { Mar }\end{array}$} & \multirow{2}{*}{$\begin{array}{l}\text { Abr- } \\
\text { Jun }\end{array}$} & \multirow{2}{*}{$\begin{array}{l}\text { Jul- } \\
\text { Set }\end{array}$} & \multirow{2}{*}{$\begin{array}{l}\text { Out-- } \\
\text { Dez }\end{array}$} \\
\hline \multirow{2}{*}{ Etapa 1} & Ativ. 1.1 & & & & & & & & & & & & \\
\hline & Ativ. 1.2 & & & & & & & & & & & & \\
\hline Etapa 2 & Ativ. 2.1 & & & & & & & & & & & & \\
\hline Etapa 2 & Ativ. 2.2 & & & & & & & & & & & & \\
\hline Etapa 3 & Ativ. 3.1 & & & & & & & & & & & & \\
\hline Etapa 4 & Ativ. 4.1 & & & & & & & & & & & & \\
\hline Etapa 4 & Ativ. 4.2 & & & & & & & & & & & & \\
\hline
\end{tabular}

\section{Gestão Estratégica}

\begin{tabular}{|c|c|c|c|}
\hline Objetivos & Metas & Indicadores & Acompanhamento \\
\hline $\begin{array}{lr}\text { Aumentar o } & \text { nível de } \\
\text { alfabetização } & \text { dos } \\
\text { alunos em } & \text { Língua } \\
\text { Portuguesa } & \end{array}$ & $\begin{array}{l}\text { Aumentar o número de } \\
\text { aprovações nas } \\
\text { respectivas disciplinas em } \\
5 \% \text { ao final do primeiro } \\
\text { ano de projeto; } 10 \% \text { no } \\
\text { segundo ano e } 15 \% \text { no } \\
\text { terceiro. }\end{array}$ & $\begin{array}{l}\text { Avaliações } \\
\text { internas ao final } \\
\text { dos anos de: } \\
2016,2017 \text { e } \\
2018 .\end{array}$ & $\begin{array}{l}\text { Controle bimestral } \\
\text { do rendimento das } \\
\text { turmas e definição } \\
\text { de ações corretivas } \\
\text { para } \\
\text { planejamento (caso } \\
\text { seja necessário), } \\
\text { levando } \\
\text { consideração em } \\
\text { também o feedback } \\
\text { de alunos e } \\
\text { professores. }\end{array}$ \\
\hline
\end{tabular}




\begin{tabular}{|c|c|c|c|}
\hline & $\begin{array}{l}\text { Alcançar a meta } \\
\text { estabelecida na avaliação } \\
\text { IDEB para Língua } \\
\text { Portuguesa até o final do } \\
\text { projeto. }\end{array}$ & $\begin{array}{l}\text { Resultado da } \\
\text { avaliação externa } \\
\text { Prova Brasil para } \\
\text { o ano de 2017. }\end{array}$ & $\begin{array}{l}\text { Análise bimestral } \\
\text { de habilidades } \\
\text { necessárias. } \\
\text { Discussão } \\
\text { estabelecimento de } \\
\text { ações específicas } \\
\text { com base nas } \\
\text { avaliações anuais e } \\
\text { nos simulados. }\end{array}$ \\
\hline & $\begin{array}{l}\text { Aumentar o número de } \\
\text { busca por livros na } \\
\text { biblioteca (empréstimos) } \\
\text { em } 10 \% \text { no final do } \\
\text { primeiro ano de projeto; } \\
20 \% \text { no segundo ano e } \\
30 \% \text { no terceiro. }\end{array}$ & $\begin{array}{l}\text { Retirada de livros } \\
\text { em dezembro de } \\
2016, \quad 2017 \quad \text { e } \\
2018\end{array}$ & $\begin{array}{l}\text { Reuniões mensais } \\
\text { com o professore } \\
\text { readaptado que } \\
\text { cuida da biblioteca } \\
\text { e com o professor } \\
\text { da classe. Passar } \\
\text { atividades e tarefas } \\
\text { que envolvam } \\
\text { leitura de livros e } \\
\text { pesquisas } \\
\text { internet. }\end{array}$ \\
\hline \multirow{2}{*}{$\begin{array}{l}\text { Desenvolver } 0 \\
\text { vocabulário infantil e as } \\
\text { técnicas de redação }\end{array}$} & $\begin{array}{l}\text { Proporcionar um } \\
\text { vocabulário culto para que } \\
\text { a criança consiga } \\
\text { compreender e interpretar } \\
\text { os gêneros textuais } \\
\text { aumentando gradualmente } \\
\text { em } 10 \% \text { ao ano os acertos } \\
\text { nas questões } \\
\text { interpretativas }\end{array}$ & $\begin{array}{l}\text { Avaliações } \\
\text { internas ao final } \\
\text { dos anos } \\
2016, \quad 2017 \quad \text { e } \\
2018\end{array}$ & $\begin{array}{l}\text { Controle bimestral } \\
\text { do rendimento das } \\
\text { turmas e definição } \\
\text { de ações corretivas } \\
\text { para o próximo } \\
\text { bimestre. }\end{array}$ \\
\hline & $\begin{array}{l}\text { Aumentar ao final do } 10 \\
\text { ano do projeto em } 10 \% \text { o } \\
\text { índice de coerência e } \\
\text { coesão nas escritas } \\
\text { espontâneas dos alunos, } \\
\text { em } 20 \% \text { no segundo ano e } \\
\text { em } 25 \% \text { ao final do } 30 \text { ano }\end{array}$ & $\begin{array}{l}\text { Resultado da } \\
\text { avaliação interna } \\
\text { de produção de } \\
\text { texto ao final dos } \\
\text { anos 2016,2017 e } \\
2018\end{array}$ & \begin{tabular}{lr}
\multicolumn{2}{l}{ Acompanhamento } \\
mensal & pelo \\
caderno & de \\
redações, & \\
correções & coletivas \\
de & textos \\
escolhidos & de \\
alunos sem autor.
\end{tabular} \\
\hline \multirow{2}{*}{$\begin{array}{l}\text { Desenvolver a } \\
\text { capacidade lógica } \\
\text { matemática dos } \\
\text { educandos através de } \\
\text { atividades práticas com } \\
\text { auxilio de softwares }\end{array}$} & $\begin{array}{lr}\text { Aumentar a compreensão } \\
\text { das escritas matemáticas } \\
\text { tal qual situações } \\
\text { problemas em } 10 \% \text { ao ano }\end{array}$ & $\begin{array}{l}\text { Resultado da } \\
\text { avaliação externa } \\
\text { Prova Brasil e } \\
\text { SARESP para o } \\
\text { ano de 2017. }\end{array}$ & $\begin{array}{l}\text { Análise bimestral } \\
\text { de habilidades } \\
\text { necessárias. Ações } \\
\text { necessárias de } \\
\text { correção } \quad \text { de } \\
\text { estratégias. }\end{array}$ \\
\hline & $\begin{array}{l}\text { Aumentar o número de } \\
\text { aprovações } \\
\text { matemática em } 5 \% \text { ao } \\
\text { final do } 10 \text { ano do Projeto, }\end{array}$ & $\begin{array}{l}\text { Resultados das } \\
\text { avaliações } \\
\text { internas ao final } \\
\text { dos anos de: } 2016\end{array}$ & $\begin{array}{l}\text { Controle bimestral } \\
\text { do rendimento das } \\
\text { turmas e definição } \\
\text { de ações corretivas }\end{array}$ \\
\hline
\end{tabular}


$10 \%$ no segundo ano e 1 a 2018.

para 0 próximo

$15 \%$ no terceiro ano

bimestre

\section{Continuidade do projeto}

O Projeto terá continuidade com o enriquecimento do acervo tecnológico, compra de novos softwares e manutenção da sala de informática, oferecendo novidades e atualizando os professores de forma a oferecer 0 suporte necessário para o desenvolvimento do fazer pedagógico.

A troca de experiências será outro fator fundamental que enriquecerá e trará fortalecimento para os professores que tenham maior dificuldade, que em conjunto com o orientador pedagógico, aos poucos e observada a consolidação das novas práticas, mostrará sites como da fundação Lemamm - Khan Academy e tantos outros que trarão contribuições positivas para o processo de ensino-aprendizagem na Unidade Escolar em que atuo.

Garantirei o investimento financeiro quando os recursos acabarem buscando parcerias com empresas de meu município que acreditam na educação e através dos recursos obtidos da cantina mantida pela escola.

\section{MARKETING E COMUNICAÇÃO}

\section{Lançamento do projeto}

O lançamento do projeto será feito em parceria com a Secretaria Municipal da Educação num evento marcado no período manhã para atingir também os alunos. Serão elaborados convites pelos alunos dos 50 anos com a programação do evento. Será realizada uma escolha e confeccionado o convite vencedor. Os convites serão distribuídos a todos os alunos para encaminharem a seus pais ou responsáveis. Também será disponibilizado na fanpage da escola, encaminhado por e-mail às demais unidades escolares e autoridades dos poderes executivo e legislativo. Esse evento será um marco de extrema importância para nossa instituição escolar a qual se apropriará de novas tecnologias almejando uma educação de excelência.

A programação seguirá protocolo de inaugurações com seus discursos breves e os alunos apresentarão atividades relacionadas ao dia a dia da utilização e benefícios desses recursos na escola. Ficando assim 0 roteiro:

- Fala da diretora: Fará um breve relato sobre o trabalho desenvolvido na Sala de Informática e os benefícios que trará aos alunos;

- Fala da Secretária Municipal de Educação Sra. Maria Tereza Ribeiro;

- Apresentação de uma crônica ou texto dissertativo pelos alunos sobre a importância da tecnologia na vida das pessoas;

- Os computadores estarão ligados já com os softwers e uma classe será convidada para jogar afim de que todos os presentes compartilhem esse novo período de mudanças.

Encerrado o evento os presentes serão convidados para um coffe breack.

Canais de comunicação e acompanhamento do projeto

\section{Marketing interno}

O canal de comunicação com a equipe será feito por e-mail: emebcarlina@tiete.sp.gov.br, individualmente em HTPEs (Hora de Trabalho Pedagógico individualizado) e em HTPCs (Hora de Trabalho Pedagógico Coletivo) para troca de experiências e maior envolvimento dos docentes mensalmente.

\section{Marketing externo}

O projeto será divulgado de duas formas: por meio de vídeos e fotos na fanpage da escola para que toda comunidade tenha acesso aos trabalhos realizados e postado quinzenalmente e por meio dos jornais da 
cidade com fotos e texto explicando o projeto implantado com comunicação bimestral.

Parceiros estratégicos

1) Gráficos Informática - Loja de equipamentos e manutenção de computadores e periféricos localizada próxima a escola.

Este parceiro garantirá a manutenção dos equipamentos.

A escola fará a divulgação da empresa parceira em sua fanpage, assim como fará a aquisição de cartuchos de tinta.

A parceria será conseguida devido ao bom relacionamento que a escola tem com a loja há muitos anos adquirindo cartuchos e materiais para secretaria por praticarem ótimos preços.

2) Camargo Embalagens - Empresa próspera do município que produz embalagens para grandes empresas do ramo de alimentos.

Este parceiro garantirá a aquisição de softwares e pagamento para capacitações futuras.

A escola divulgará esta parceria com a imagem de empresa que acredita na educação e pensa de maneira sustentável garantindo a saúde e será feita pela fanpage e jornais locais.

Esta empresa será nossa parceira pois a família de acionistas é muito comprometida com projetos educacionais, sempre são solícitos aos pedidos da escola e o grupo gestor de nossa Unidade Escolar possui um vínculo de amizade.

\section{Divulgação de resultados}

Os resultados serão divulgados ao final de cada ano através das reuniões de pais, pela equipe gestora que demonstrará no datashow os resultados dos avanços dos alunos no desenvolvimento do projeto mostrando as avaliações e comparando-as com 0 ano anterior. $O$ acompanhamento durante o processo também ocorrerá mas será feito através da página da fanpage. A estratégia utilizada para a divulgação ao final do ano também será complementada pelos próprios educandos, que darão depoimentos de como eram as aulas antes e depois da implantação das novas tecnologias.

\section{EQUIPE DO PROJETO}

\section{Equipe interna}

\begin{tabular}{|l|l|l|l|l|}
\hline \multicolumn{1}{|c|}{ Cargo } & \multicolumn{1}{|c|}{ Formação } & $\begin{array}{r}\text { Tempo na } \\
\text { escola }\end{array}$ & Experiência anterior & $\begin{array}{c}\text { Responsável } \\
\text { pelas } \\
\text { atividades: }\end{array}$ \\
\hline Diretor & Pós-graduada & 9 anos & $\begin{array}{l}\text { PEB I coordenadora } \\
1.1,1.2,2.1,3.1, \\
4.1\end{array}$ \\
\hline Assessor & Graduada & 1 ano & PEB I & $1.1,2.1,3.1,4.1$ \\
\hline $\begin{array}{l}\text { Orientador } \\
\text { Pedagógico }\end{array}$ & Mestrado & 1 ano & PEB II & $1.2,3.1,4.1$ \\
\hline Secretário & Graduado & 2 anos & Vendedor & 4.1 \\
\hline $\begin{array}{l}\text { Agente } \\
\text { Organização } \\
\text { Escolar }\end{array}$ & Ensino Médio & 12 anos & Secretário & $1.1,2.1$ \\
\hline
\end{tabular}




\section{Sandra Novaes Franzini Sutilo}

\begin{tabular}{|l|l|l|l|l|}
\hline Professor I & Pós-graduada & 5 anos & $\begin{array}{l}\text { Professora de } \\
\text { Informática }\end{array}$ & $2.1,4.1$ \\
\hline Professor I & Graduada & 11 anos & PEB I & $3.1,4.1$ \\
\hline Professor I & Graduada & 15 anos & PEB I & $3.1,4.1$ \\
\hline
\end{tabular}

\section{Profissionais externos}

\begin{tabular}{|l|l|l|}
\hline Tipo de profissional & Competências necessárias & Participação no projeto \\
\hline Eletricista & Curso de elétrica & 1.1 \\
\hline Pintor & Curso de pintura & 1.1 \\
\hline Técnico de Informática & Curso de T.I & 1.1 \\
\hline Professor Formador & $\begin{array}{l}\text { Graduado em Port./Matemática ou } \\
\text { Pedagogia com domínio em softwares }\end{array}$ & 2.1 \\
\hline
\end{tabular}

\section{PLANO FINANCEIRO Investimentos (despesas de capital)}

\section{Plano de Empreendimento}

\begin{tabular}{|l|c|c|c|}
\hline \multicolumn{1}{|c|}{ Obras e infraestrutura } & Ano 1 & Ano 2 & Ano 3 \\
\hline Eletricista & $1.200,00$ & 0,00 & 0,00 \\
\hline Pintor & 800,00 & 0,00 & 0,00 \\
\hline Técnico de Informática & $1.200,00$ & 0,00 & 0,00 \\
\hline $\begin{array}{l}\text { Manutenção } \\
\text { ar- condicionado }\end{array}$ & & 120,00 & 120,00 \\
\hline Total & $3.200,00$ & 120,00 & 120,00 \\
\hline
\end{tabular}

\begin{tabular}{|l|l|l|l|}
\hline Material permanente & Ano 1 & Ano 2 & Ano 3 \\
\hline 2 Computadores & $3.796,10$ & 0,00 & 0,00 \\
\hline Softwares pedagógicos & $1.590,00$ & $1.000,00$ & 788,28 \\
\hline Ar condicionado & $1.899,90$ & 0,00 & 0,00 \\
\hline Data show & $1.895,00$ & 0,00 & 0,00 \\
\hline Total & $\mathbf{9 . 1 8 1 , 0 0}$ & $\mathbf{1 . 0 0 0 , 0 0}$ & $\mathbf{7 8 8 , 2 8}$ \\
\hline
\end{tabular}




\section{Despesas correntes}

\section{PLEM Plano de Empreendimento}

\begin{tabular}{|l|l|l|l|}
\hline \multicolumn{1}{|c|}{ Material de consumo } & \multicolumn{1}{c|}{ Ano 1 } & \multicolumn{1}{c|}{ Ano 2 } & \multicolumn{1}{c|}{ Ano 3 } \\
\hline Fios elétricos/Cabos rede & 850,00 & 0,00 & 0,00 \\
\hline Interruptores/Tomadas & 590,00 & 0,00 & 0,00 \\
\hline Materiais para pintura & 1200,00 & 0,00 & 0,00 \\
\hline Cartuchos/ Toners & $1.680,00$ & $1.680,00$ & $1.680,00$ \\
\hline Papéis/Materiais escritório & $1.950,00$ & $1.950,00$ & $1.950,00$ \\
\hline Plano internet/Telefonia & $1.200,00$ & $1.200,00$ & 1200,00 \\
\hline Total & $\mathbf{7 . 4 7 0 , 0 0}$ & $\mathbf{4 . 8 3 0 , 0 0}$ & $\mathbf{4 . 8 3 0 , 0 0}$ \\
\hline
\end{tabular}

\begin{tabular}{|l|l|l|l|}
\hline Serviços de terceiros & Ano 1 & Ano 2 & Ano 3 \\
\hline Eletricista & 1200,00 & 0,00 & 0,00 \\
\hline Pintor & 800,00 & 0,00 & 0,00 \\
\hline Instalação do ar- condicionado & 540,00 & 0,00 & 0,00 \\
\hline Manutenção do ar- condicionado & 0,00 & 120,00 & 120,00 \\
\hline Professor Formador & 306,50 & 245,20 & 122,60 \\
\hline Total & $\mathbf{2 . 8 4 6 , 5 0}$ & $\mathbf{3 6 5 , 2 0}$ & $\mathbf{2 4 2 , 6 0}$ \\
\hline
\end{tabular}

\section{Recursos totais}

\begin{tabular}{|l|l|l|l|l|}
\hline Tipo de item & Ano 1 & Ano 2 & Ano 3 & Total \\
\hline Despesas de Capital & $12.381,00$ & $1.120,00$ & 908,28 & $14.409,28$ \\
\hline Obras e infraestrutura & $3.200,00$ & 120,00 & 120,00 & $3.440,00$ \\
\hline Material permanente & $9.181,00$ & $1.000,00$ & 788,28 & $10.969,28$ \\
\hline Despesas Correntes & $10.316,50$ & $\mathbf{5 . 1 9 5 , 2 0}$ & $\mathbf{4 . 9 5 2 , 6 0}$ & $\mathbf{2 0 . 4 6 4 , 3 0}$ \\
\hline Material de consumo & $7.470,00$ & $4.830,00$ & $4.830,00$ & $17.130,00$ \\
\hline Gastos com locomoção & 0,00 & 0,00 & 0,00 & 0,00 \\
\hline Serviços de terceiros & $2.846,50$ & 365,20 & 122,60 & $3.334,30$ \\
\hline Total de recursos do edital & $\mathbf{2 2 . 6 9 7 , 5 0}$ & $\mathbf{6 . 3 1 5 , 2 0}$ & $\mathbf{5 . 8 6 0 , 8 8}$ & $\mathbf{3 4 . 8 7 3 , 5 8}$ \\
\hline Gastos adicionais & 0,00 & $\mathbf{0 , 0 0}$ & $\mathbf{0 , 0 0}$ & $\mathbf{0 , 0 0}$ \\
\hline Recursos totais & $\mathbf{2 2 . 6 9 7 , 5 0}$ & $\mathbf{6 . 3 1 5 , 2 0}$ & $\mathbf{5 . 8 6 0 , 8 8}$ & $\mathbf{3 4 . 8 7 3 , 5 8}$ \\
\hline
\end{tabular}

\section{Categoria em que o projeto se enquadra : Categoria B}




\section{Contrapartida}

\begin{tabular}{|l|l|l|}
\hline Profissionais & Horas dedicadas ao projeto & Valor médio/hora \\
\hline Professor Responsável & 225 & 12,26 \\
\hline Direção & 240 & 21,70 \\
\hline Orientador Pedagógico & 150 & 19,20 \\
\hline Agente de Organização Escolar & 60 & 7,00 \\
\hline Secretário & 120 & 8,25 \\
\hline Total de contrapartida & $\mathbf{7 9 5}$ & $\mathbf{1 3 , 6 8}$ \\
\hline
\end{tabular}

